\title{
Determining the value contribution of selexipag for the treatment of pulmonary arterial hypertension (PAH) in Spain using reflective multi-criteria decision analysis (MCDA)
}

Alberto Jiménez ${ }^{1}$, Arantza Ais², Amélie Beaudet ${ }^{3}$ and Alicia Gil ${ }^{4^{*}}$ (i)

\begin{abstract}
Background: Pulmonary Arterial Hypertension (PAH) is a chronic rare disease that can lead to serious cardiovascular problems and death. Additional treatments that increase effectiveness, that are safe and with a convenient administration that improve outcomes and quality of life for patients are needed. The aim of this study was to assess the value contribution of the new, oral prostacyclin receptor agonist, selexipag, for PAH treatment in Spain through reflective Multicriteria Decision Analysis (MCDA) methodology.
\end{abstract}

Methods: A comprehensive literature review was performed to develop an evidence matrix, composed of twelve quantitative criteria and four contextual criteria, based on an EVIDEM MCDA framework adapted to orphan drugs evaluation by the Spanish region of Catalonia. Quantitative performance scores, qualitative impact of contextual criteria and individual reflections from stakeholders were collected for each MCDA framework criteria. The value contribution of selexipag to PAH treatment compared to inhaled iloprost was calculated.

Results: Oral selexipag for PAH treatment was considered as a treatment which adds value, compared to iloprost, in the following MCDA quantitative criteria: comparative efficacy, patient reported outcomes, preventive benefit, therapeutic benefit, other medical costs and other non-medical costs, without significant differences in safety profile but with a higher acquisition cost than inhaled iloprost.

Conclusions: Selexipag was considered to provide value to PAH treatment. It was perceived as an intervention indicated for a severe rare disease with high unmet needs, supported by high quality clinical evidence. When compared to inhaled iloprost, oral selexipag has demonstrated improvements in efficacy and patient reported outcomes, with a similar safety profile and some additional costs.

Reflective MCDA provided a standardised, transparent approach to evaluate multiple criteria relating to the overall value contribution of selexipag to PAH treatment facilitating decision-making.

Keywords: Multi-criteria decision analysis, MCDA, Rare disease, Pulmonary arterial hypertension, Selexipag, lloprost

\footnotetext{
* Correspondence: agil@omakaseconsulting.com

${ }^{4}$ Omakase Consulting S.L., Madrid, Spain

Full list of author information is available at the end of the article
}

(c) The Author(s). 2018 Open Access This article is distributed under the terms of the Creative Commons Attribution 4.0 International License (http://creativecommons.org/licenses/by/4.0/), which permits unrestricted use, distribution, and reproduction in any medium, provided you give appropriate credit to the original author(s) and the source, provide a link to the Creative Commons license, and indicate if changes were made. The Creative Commons Public Domain Dedication waiver (http://creativecommons.org/publicdomain/zero/1.0/) applies to the data made available in this article, unless otherwise stated. 


\section{Background}

Pulmonary Arterial Hypertension (PAH) is a chronic rare disease which causes a progressive right ventricular dysfunction that can lead to severe right heart cardiac insufficiency and death [1]. PAH prevalence is estimated at 15-50 cases per million of inhabitants with a median survival time after diagnosis of 2.8 years [2, 3] when untreated. Current treatments for $\mathrm{PAH}$ aim to improve the physical function and quality of life of patients, but there is no cure to date. Drugs are available for three key pathogenic pathways associated with $\mathrm{PAH}$ : the nitric oxide pathway, the endothelin pathway, and the prostacyclin pathway. Phosphodiesterase type 5 inhibitors (PDE5i) and endothelin receptor antagonists (ERAs) are used as first line treatments mainly due to their convenient oral administration and the long clinical experience [4].

The severity of PAH is typically determined according to the classification of the World Health Organization (WHO Functional Classification (FC)) for PAH [5], which classify patients into four different classes: FC I to FC IV, where the higher classes indicates more severe disease status. When untreated, median survival is only 6 months for patients in WHO FC IV, compared with 2.5 years for those in WHO FC III, and 6 years for those in WHO FC I and II [5]. Therapies targeting the prostacyclin pathway are recommended for patients in FC II-IV [1], but their use has been limited by their mode of administration [6]: continuous parenteral administration or frequent inhaled administration (6-9 times daily) [7]. Moreover, they were approved only based on short-term, monotherapy studies, as these were the first treatments available. Therefore, there is a need for an effective, safe and convenient treatment acting on the prostacyclin pathway in order to prevent disease progression and a higher WHO FC classification.

Selexipag is a new selective agonist of prostacyclin receptor (IP) which is administered orally twice a day. Stimulation of IP by selexipag and its active metabolite causes vasodilatory, antiproliferative and antifibrotic effects. Selexipag is indicated for the long-term treatment of PAH in adult patients with FC II-III, as combination therapy in patients insufficiently controlled with an ERA and/or a PDE-5 inhibitor, or as monotherapy in patients who are not candidates for these treatments [8]. The efficacy of selexipag has been demonstrated in a large $(n=1156)$, placebo-controlled, long-term phase III clinical trial (GRIPHON study) [9]. Selexipag significantly reduced the risk of occurrence of morbidity-mortality events by $40 \%$, the risk of hospitalisation by $33 \%$ and disease progression by $64 \%$. The most frequent treatment-related adverse events (AEs) reported were headache, diarrhoea, jaw pain and nausea [10]. According to current clinical practice in PAH in Spain [1], selexipag could be positioned as an alternative to iloprost, the only non-parenteral drug acting on the prostacyclin pathway available in Spain which is administered by inhalation, in 20-min sessions, between 6 and 9 times daily [10].

Healthcare reimbursement decisions for drugs indicated to treat rare diseases are challenging. Thus, assessment of the value and the most adequate positioning within healthcare systems of a drug indicated for the treatment of a rare disease should be holistic, requiring a broader perspective, not limited to the traditional criteria of efficacy, safety and cost [11, 12]. Reflective multi-criteria decision analysis (MCDA) offers a framework with which to make complex healthcare decisionmaking problems into a comprehensive set of criteria relevant for establishing the value of a drug in an explicit, holistic and systematic way $[13,14]$.

The aim of this study was to assess the value contribution of selexipag relative to inhaled iloprost for $\mathrm{PAH}$ treatment through reflective MCDA methodology from the perspective of all relevant key stakeholders, including evaluators, clinicians, regional decision makers, hospital pharmacists and patients, in Spain.

\section{Methods \\ Study design}

The study was designed according to MCDA methodology $[13,14]$, using the criteria from the MCDA framework specifically adapted for the appraisal of drugs indicated to treat rare diseases in Spain [15]. Inhaled iloprost was the chosen comparator [1]. A literature review was conducted to obtain relevant information on the disease and its current management in Spain as well as relevant evidence for both compared products. Information was structured into an evidence matrix. This matrix was scored by a broad multidisciplinary panel of Spanish stakeholders involved in healthcare decisionmaking. Scores were analysed quantitatively. Comments and reflections behind experts' scores were collected in a qualitative manner.

\section{Literature review}

A literature review was conducted to identify available evidence for selexipag and inhaled iloprost. Available evidence was used to create the MCDA evidence matrix.

Two types of documents were searched: published evidence in biomedical databases and specific product evaluations for selexipag and inhaled iloprost by official healthcare evaluation bodies.

Published evidence was searched in PubMed and MEDES (Medicina en Español) [16] databases in order to answer the following search question: What is the available evidence on epidemiology, health outcomes, unmet needs and economic consequences for the evaluation of drugs indicated for treatment of PAH in Spain? 
The PICOTS (population, intervention, comparison, outcomes, time span and studies) search strategy was used $[17,18]$. The literature review in biomedical databases included published studies from 2007 to 2017.

Specific product evaluations for selexipag and inhaled iloprost were searched in official European and Spanish healthcare evaluation bodies' webpages [e.g. European Medicines Agency (EMA) [19], Spanish Medicines Agency (AEMPS) [20] and Spanish regional and hospital evaluations [21]]. All evaluations found were included, regardless of the date of publication.

At the time of the study start, the reimbursed price for selexipag had not yet been established in Spain, so a hypothetical price was used. The approved list price [22] was later used in the second phase of the study.

\section{Reflective MCDA tool and evidence matrix development}

The MCDA framework used was the one adapted and adopted for the appraisal of drugs indicated to treat rare diseases developed by the Catalonian Regional Healthcare Service (Catsalut) [15]. This adapted MCDA framework is based on the EVIDEM framework (version 4.0) [23] and composed of a total of 16 criteria (Table 1). These criteria are structured into two sections: the MCDA Core Model composed of 12 quantitative criteria focused on product evaluation and the MCDA Contextual Tool composed of 4 contextual criteria focused on the consideration of the context surrounding decision-making).

To compare selexipag with inhaled iloprost in the comparative criteria of the MCDA framework, data from randomised control trials from both interventions were used and compared in a descriptive manner.

\section{Expert panel design and conduct of the study}

The study was conducted with a multidisciplinary panel of 28 people involved in the management of $\mathrm{PAH}$ treatments and decision-making in Spain, including evaluators, clinicians, regional decision makers, hospital pharmacists from different regions and a patient representative in order to collect insights from a broad range of perspectives.

The study was conducted in two phases: a first face to face meeting with seven experts in the evaluation and management of PAH treatments in Spain, where participants received prior training on reflective MCDA methodology. The experts scored the evidence matrix and the reflections behind the score results were collectively discussed to assess the value contribution of selexipag. This first phase was conducted in November 2016.
Table 1 MCDA EVIDEM framework version 4.0 adapted to evaluation of medicines indicated for rare diseases

QUANTITATIVE CRITERIA: MCDA Core Model

DOMAIN: Disease needs

Disease severity

Unmet needs

DOMAIN: Comparative outcomes of interventions (selexipag vs iloprost)

Comparative efficacy/effectiveness

Comparative safety/tolerability

Comparative patient-perceived health/patient reported outcomes (PRO)

DOMAIN: Type of benefit provided by selexipag

Type of preventive benefit

Type of therapeutic benefit

DOMAIN: Comparative economic consequences of interventions (selexipag vs iloprost)

Comparative cost of intervention

Comparative other medical costs

Comparative other non-medical costs

DOMAIN: Knowledge about selexipag

Quality of evidence

Expert consensus/clinical practice guidelines (CPG)

CONTEXTUAL CRITERIA: MCDA Contextual Tool

Population priorities and access

Common goals and specific interests

System capacity and appropriate use of intervention

Opportunity costs and affordability

The second phase of the study, performed in June 2017, had the objective of validating the results obtained in the first phase and improve the robustness of the results by increasing the sample size. This second part involved 21 participants and was performed using an online platform (Jotform) [24]. Prior to study start, participants received on-line training on reflective MCDA methodology.

\section{Data analysis}

Data were collected from each participant, transferred to a common database and analysed with Microsoft Excel. A descriptive analysis of each criterion was conducted. The evaluation of quantitative criteria was performed using a direct rating scale, which varied depending on the type of criteria: from 0 to +5 for non-comparative criteria and from -5 to +5 for comparative criteria. Results of quantitative criteria scoring were given in the form of mean \pm standard deviation (SD). The value contribution $(\mathrm{VCx})$ of each quantitative criterion was calculated as the product of its normalised weight (Wx, $\left.\sum \mathrm{Wx}=1\right)$ and standardised score $(\mathrm{Sx}=$ score $/ 5)$. Total 
value estimate (VT) is the sum of all criteria value contributions:

$$
\mathrm{VT}=\sum_{x=1}^{\mathrm{n}} \mathrm{VC}_{x}=\sum_{x=1}^{n}\left(\mathrm{~W}_{x} \times \mathrm{S}_{x}\right)
$$

The evaluation of contextual criteria was performed on a qualitative scale with three options (positive, neutral or negative impact) and scores were transformed into a numerical scale $(+1,0$ and -1 points respectively).

A two-way ANOVA test of the score means for each criterion obtained from the two study phases was carried out to assess potential differences between scores from both phases of the study. All the quantitative criteria, except for "cost of intervention" (because the price used in both phases of the study was different) were considered in this analysis.

\section{Treatment of inconsistencies}

Scores attributed to human error or failure to understand the criteria (e.g.: a higher score assigned to the criteria "comparative cost of the intervention" for an intervention that is more expensive than the comparator) were considered as inconsistencies, excluded from the analysis and replaced using the mean substitution.

\section{Results}

\section{Literature review}

The evidence matrix was constructed with a total of 36 identified references (Fig. 1) found in biomedical databases $(n=15)$, documents from official sources (i.e.: EMA, AEMPS) $(n=2)$, regional and hospital evaluations $(n=1)$, clinical guidelines or protocols $(n=2)$ and online grey literature $(n=16)$.
The literature review for the first phase was conducted in October 2016 and then updated in May 2017 for the second phase. To calculate the budget impact of selexipag, and in the absence of any public data source, the number of target patients used was based on estimates provided by Actelion Pharmaceuticals Ltd. (personal communication; reference on file).

\section{Performance scores based on evidence and participants' insights on selexipag}

The scores resulting from both phases of the study for each criterion were analysed separately. There were no significant differences between the score means from both studies for any of the analysed criteria (95\% CI $p>0.05)$. Thus, both samples were combined into a single database and further analysed as shown in Fig. 2. Only statistically significant differences reported across participants' professional profiles were mentioned.

"Severity of disease" scored $4.5 \pm 0.5$ (mean score \pm SD) on a scale of 0 to 5 , reflecting experts' perception of its impact on mortality and patient's quality of life. Although all participants assigned a high score value to this criterion, statistically significant differences were only reported between scores from clinicians and healthcare decision makers (mean score 4.81 vs 4.17 respectively; $95 \%$ CI: 0.04 to 1.26 ; $p=0.03$ ). The "Unmet needs" criterion scored $4.1 \pm 0.8$ on a scale of 0 to 5 , as all participants agreed that PAH is a condition with important unmet needs, mainly with regards to the lack of curative and more effective treatments, the need for earlier diagnosis and for treatments with a more convenient route of administration and posology.

Selexipag's "comparative effectiveness" versus iloprost scored $2.3 \pm 1.9$ on a scale of -5 to 5 . Most participants assigned a positive score to this criterion (19 out of 21).

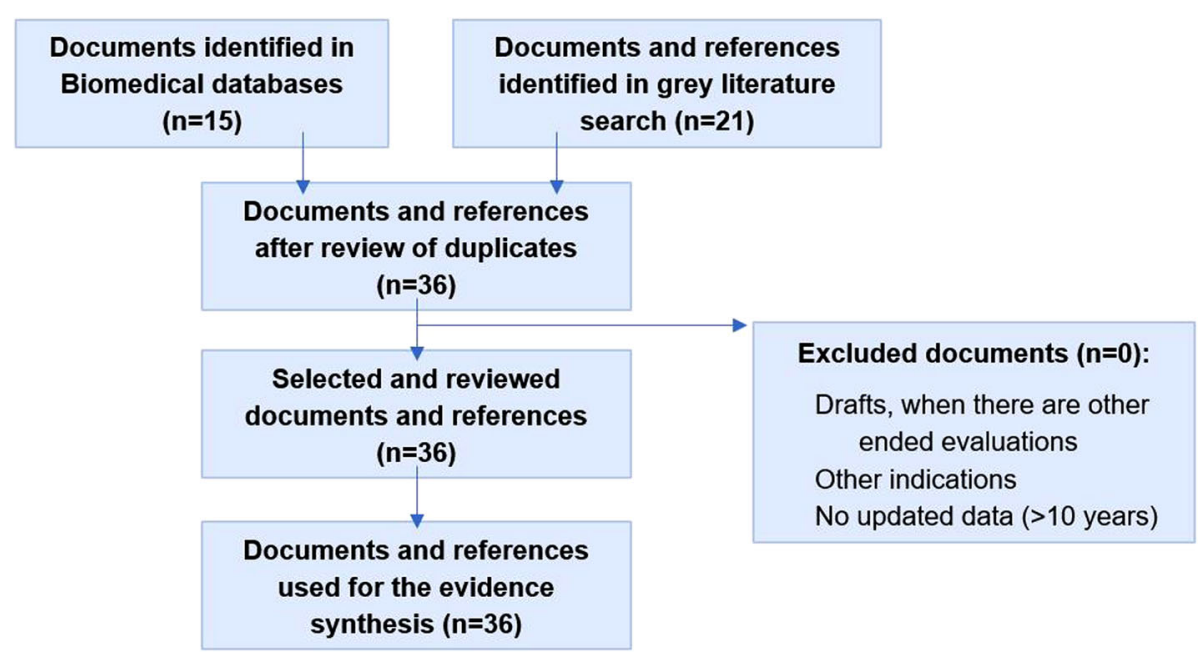

Fig. 1 PRISMA diagram [34] of the literature review performed 


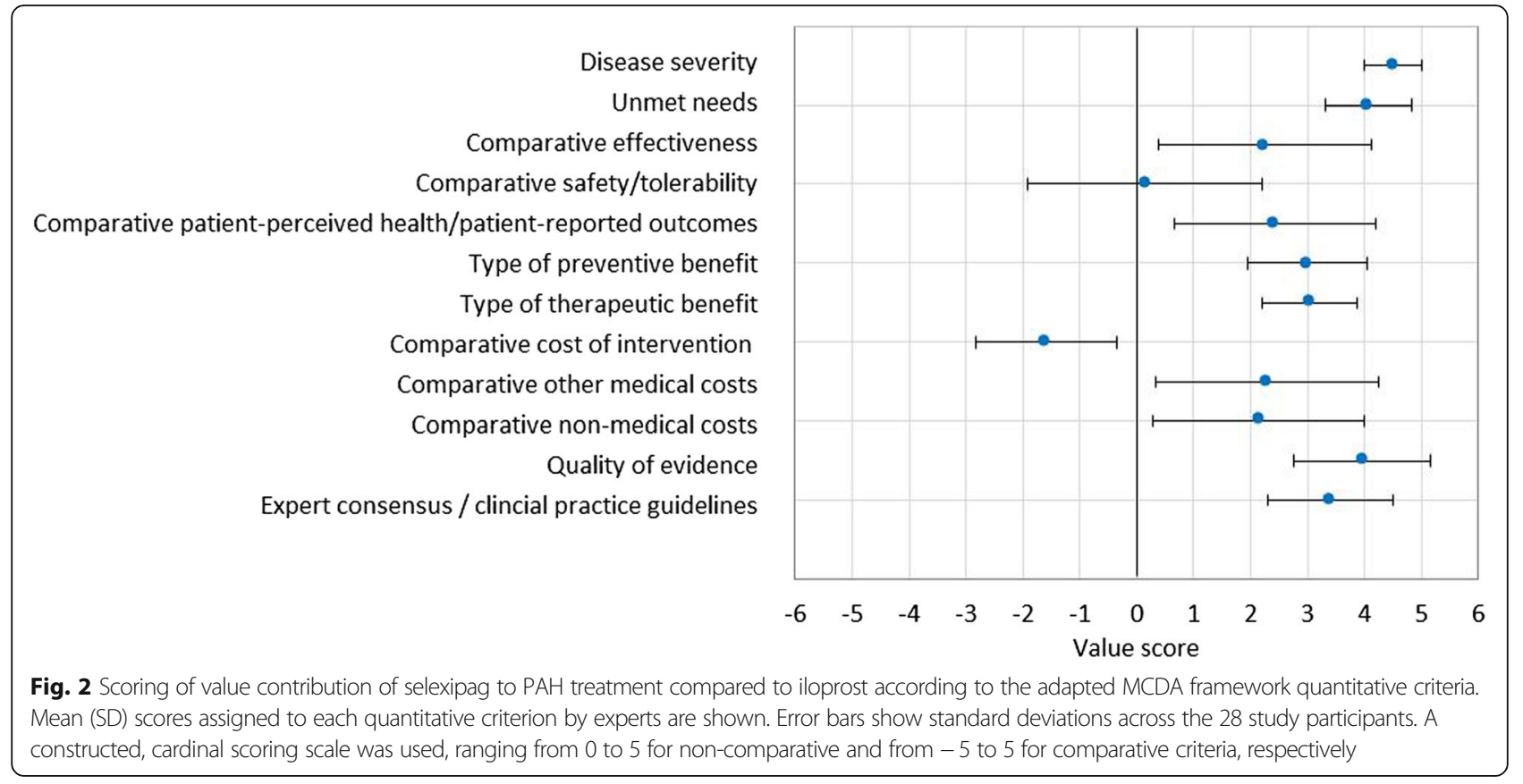

Experts pointed out that the positive score in the "comparative efficacy" criterion for selexipag was due to the robust data obtained in clinical trials compared to placebo (no direct comparative data for selexipag versus iloprost were available). There were statistically significant differences in opinions for this criterion between clinicians and hospital pharmacists (3.3 vs 1 , respectively, $95 \%$ CI: 0.40 to $4.15 ; p=0.01$ ). No differences in terms of "comparative safety/tolerability" were reported, as this criterion scored $0.1 \pm 2.1$ on a scale of -5 to 5 , due to the similar rate of adverse events reported with selexipag and inhaled iloprost. "Comparative patient reported outcomes (PROs)" scored $2.4 \pm 1.8$ on a scale of -5 to 5 . Selexipag was perceived as a drug capable of providing value in terms of patient's quality of life compared to inhaled iloprost due to the convenience of its route of administration and posology: orally for selexipag versus inhaled for iloprost, and the dosing schedule (two times per day vs 6-9 times per day, respectively $[25,26])$. Some experts pointed out that the use of two different questionnaires in clinical trials (the CAMPHOR questionnaire [27] for selexipag and the EQ-5D VAS [28] for iloprost) did not allow the comparison of quality of life data for both drugs.

Study participants scored the criterion "preventive benefit" positively, as it scored $3.0 \pm 1.1$ on a scale of 0 to 5 , due to its mechanism of action, with the potential to stabilise the disease, reduce morbidity-mortality events and decrease the need to progress to more inconvenient treatments. The "therapeutic benefit" of selexipag was also scored positively across all participants $(3.0 \pm 0.8$ on a scale of 0 to 5$)$, based on the impact on the delay of the progression of the disease, the therapeutic convenience due to its oral administration and the impact on reducing the number of hospitalisations.. The "comparative cost" of selexipag was analysed only considering the scores from the second phase of the study, when an official approved price for selexipag in Spain was available. "Comparative cost" scored $-1.6 \pm 1.6$ on a scale of -5 to 5 . This negative score for selexipag was due to the higher price of selexipag vs inhaled iloprost (incremental cost of selexipag $9.8 \%$, ex-factory price per day $128.8 €$ vs $117.3 €$, respectively, according to the mean dosage recommended in the summary of product characteristics of both drugs ( 2 doses/day for selexipag and 7.5 inhalations/ day for iloprost) $[25,26])$. Three scoring results from the second phase in which participants scored selexipag's higher price positively were treated as inconsistences. Experts scored selexipag positively for the "comparative other medical costs" $(2.3 \pm 2.0$ on a scale of -5 to 5$)$, reflecting their perception of the economic benefits obtained due to savings on healthcare resources resulting from treatment with selexipag compared to use of iloprost. However, hospital pharmacists noted these savings had not been quantified and are not usually considered at time of inclusion of a drug into a hospital formulary. Selexipag is perceived as a therapeutic option that can produce savings in "non-medical costs" compared to iloprost (this criterion scored $2.1 \pm 1.9$ on a scale of -5 to 5), because it can improve the daily life of patients with PAH (e.g. better quality of life, reduced cost of carers). Thus, most participants considered that the cost difference between the two products would be acceptable for 
payers, due to the low prevalence of the disease, the potential cost-offsets derived from the reduction of other medical costs, the perceived improvement of patient's quality of life and other expected clinical benefits resulting from treatment with selexipag.

The quality of the evidence supporting selexipag was perceived as very good by study participants (this criterion scored $4.0 \pm 1.2$; on a scale of 0 to 5). Participants recognised the quality of both the design and the analysis of the clinical variables from the GRIPHON pivotal trial. There were statistically significant differences in the scores between clinicians and hospital pharmacists (4.8 vs 3.6 respectively; $95 \%$ CI: 0.01 to $2.4 ; p=0.04$ ) and between clinicians and healthcare decision makers $(4.8$ vs 3 respectively; $95 \% \mathrm{CI}: 0.01$ to $0.4 ; p=0.007)$. Some experts suggested the combined morbidity-mortality variable should be presented separately in study results, because the main unmet clinical need in PAH remains improvement in survival. Also, the comparison to placebo was considered as a limitation by some participants. The inclusion of selexipag in clinical practice guidelines as a reference for PAH treatment [1] was considered positively (this criterion scored $3.4 \pm 1.1$, on a scale of 0 to 5) (Table 2).

Figure 3 shows the overall value contribution of selexipag to each criterion for PAH treatment when adjusting the values of the scores obtained during the evaluation to the relative importance assigned to each criterion (weighting).

Assessment of the qualitative criteria from the adapted MCDA framework was positive for all criteria (Fig. 4). Participants scored the qualitative criteria in terms of positive, neutral or negative impact of selexipag for each criterion. Selexipag was perceived as a valuable therapeutic alternative that would have a positive impact in terms of "priority access for population", according to $71 \%$ of study participants (7\% perceived it would have a negative impact and $22 \%$ a neutral impact), as it would be expected that the classification of $\mathrm{PAH}$ as a rare disease and the severity of the disease would favour the incorporation of innovative treatments. However, even though rare disease treatment is a priority for the Spanish national healthcare system, access to new treatments in practice can be slow, according to the opinion of some participants. A total of $64 \%$ of experts agreed that selexipag was aligned with the "common goals and specific interests" item of the MCDA framework and that selexipag's access could be supported by scientific societies, patient associations and other professional groups because it matches the unmet needs identified for the disease. Although participants noted there is multidisciplinary interest from healthcare professionals in the approval of new drugs for diseases with high unmet needs, $36 \%$ participants considered there was no impact on this criterion considering the limited prevalence of PAH, which would dilute the specific pressures for inclusion of selexipag into drug formularies. Unlike for other drugs administered by intravenous injection or inhaled, study participants considered treatment with selexipag will not require specific training for patients and healthcare professionals involved in PAH. Thus, the impact on "system capacity and appropriate use of intervention" was considered positively by $75 \%$ of participants and with neutral impact for the remaining $25 \%$.

The experts perceived selexipag's budget impact as negative, due to the higher acquisition cost of selexipag compared to iloprost and the potential positive impact on disease prognosis arising from treatment with selexipag, which will, in turn, increase its prevalence. Although the budget impact was perceived negatively, a total of $64 \%$ of participants agreed that the use of selexipag would have a positive impact on the "opportunity costs and affordability" criterion, because of treatment derived clinical benefits and savings in other medical resources (i.e.: less hospital visits, less hospitalisations due to increased efficacy, training from healthcare professionals to patients on the treatment administration). Twenty-five per cent (25\%) of participants considered selexipag to have a neutral impact on this criterion and $11 \%$ considered selexipag to have a negative impact due to the perception that selexipag would increase the hospital pharmacy budget. In summary, experts believe that treatment of PAH with selexipag would be aligned with the Spanish national healthcare system priorities and the system would be prepared for management of selexipag in real clinical practice.

\section{Discussion}

The value contribution of selexipag to PAH treatment and compared to inhaled iloprost was assessed through reflective MCDA by a multidisciplinary panel of people involved in the management of PAH treatments and decision-making in Spain who scored the product's evidence matrix, which allowed a holistic value determination of selexipag, including the specific context of its appraisal in Spain.

The development and use of an on-line study platform allowed the assessment by a large enough number of regionally wide-spread experts, adding to the robustness of the study. We have been able to collect quantitative and qualitative data, including group discussions in the face-to-face panel and a broad number of individual comments in both phases of the study, reflecting the reasoning behind each participant's scoring. To our knowledge, this represents the first example of the use of an on-line platform for a study using reflective MCDA methodology for healthcare evaluation in Spain. 
Table 2 Mean scores, standard deviations and main comments from study participants for each criteria of the MCDA framework

\begin{tabular}{|c|c|c|}
\hline MCDA framework criteria & $\begin{array}{l}\text { Mean score } \pm \text { Standard } \\
\text { Deviation }\end{array}$ & Main comments from participants \\
\hline Disease severity & $4.5 \pm 0.5$ on a scale of 0 to 5 & $\begin{array}{l}\text { - "The impact of PAH on patient's health (in the most severe cases) and quality of } \\
\text { life and family environment (even in less advanced cases or responders to } \\
\text { treatment) is severe, given the irreversible nature of the process, often known by } \\
\text { patients / family, which leads to a pessimistic view about it." } \\
\text {. "Interference, often serious, when performing normal daily activities" }\end{array}$ \\
\hline Unmet needs & $4.1 \pm 0.8$ on a scale of 0 to 5 & $\begin{array}{l}\text { - "More effective and selective drugs are needed that reduce mortality and disease } \\
\text { progression in clinical trials and in real life. } \\
\text { Greater comfort than prostacyclines, so an oral treatment is welcome" } \\
\text { "Currently available drugs that act on the prostacyclin route are uncomfortable, } \\
\text { and they require time and training from patients and caregivers and interfere with } \\
\text { the proceeding of a normal daily activity." }\end{array}$ \\
\hline
\end{tabular}

Comparative efficacy/ effectiveness

Comparative safety/tolerability

Comparative patient-perceived health/patient reported outcomes (PRO)

Type of preventive benefit

Type of therapeutic benefit

Comparative cost of intervention

Comparative other medical costs
$2.3 \pm 1.9$ on a scale of -5 to 5 . "Although there is no data available for all the variables in the studies conducted with iloprost that allow comparison with selexipag, it seems that better results are seen corresponding to "death by any event." First Event. However, I believe that the impossibility of comparing more extensively with other alternatives limits the interpretation of results."

- "The results presented favour the GRIPHON study of selexipag. Not only for the inclusion of a greater number of patients (up to five times more) but also for the design and choice of the primary endpoints. The designation of morbi-mortality parameters (progression, death, hospitalization, need for IV therapy, ...) make the trial more appropriate to the actual practice, with greater statistical power and conforms to the guidelines designated in the PAH symposium at Dana Point 2007."

$0.1 \pm 2.1$ on a scale of -5 to $5 \cdot$ "I think that the lower proportion of patients who died due to "any cause", who had to interrupt the medication and who had potentially more severe undesirable effects (syncope) in the selexipag group, could be an element to be considered in the choice of selexipag with respect to iloprost."

- "It seems that iloprost has fewer adverse effects than what is mentioned, although similar at a general level."

- "Since there is no data regarding the groups treated with iloprost, even assuming that these are not studies that by their design allow direct comparison, it is not possible for me to clearly opt for any, except for the aspects related to the administration of the drugs (posology, manipulation of the inhalation device...), which evidently can suppose an interference in the quality of life of the patient derived from the greater complexity in the case of iloprost."

- "The limitation imposed by the inhalation of iloprost up to 9 times a day is important, uncomfortable and makes the patient self-conscious"

- "An oral dosage twice a day clearly improves the quality of life and the autonomy of the patient."

$3.0 \pm 1.1$ on a scale of 0 to 5

- "The reduction of mortality due to any event, and the need for hospitalization, especially taking into account the ease of administration with respect to prostanoids, confers a high therapeutic value in my opinion."

- "It does not prevent the disease, although, it stabilises and delays the appearance of new events of morbidity and mortality in relation to the disease."

$3.0 \pm 0.8$ on a scale of 0 to 5

- "The improvement in the time of progression of the disease and the increased convenience of administration are, in my opinion, favourable criteria to selexipag, especially in relation to prostanoids (aerosolized or parenteral), although the lack of effect on mortality continues to limit its therapeutic efficacy."

- "It does not cure, it stabilizes and probably helps to chronify the disease."

$-1.6 \pm 1.6$ on a scale of -5 to $\quad$ "The annual cost is substantially higher in the case of selexipag, which 5 undoubtedly hinders its acceptance by the paying entities, although the convenience in its administration, with favorable repercussion on the quality of life of the patient and caregivers, as well as improvement in the evolutionary course of the disease (with reduced costs related to, for example, the need for hospitalization) should be arguments to be considered in the negotiation with the health authorities"

- "The economic cost of selexipag is 10\% more than that of inhaled iloprost, which does not seem excessive, considering the ease of application."

$2.3 \pm 2.0$ on a scale of -5 to 5 . "The main benefit of selexipag in terms of costs lies in its potential effect on the reduction of indirect costs, such as the need for hospitalizations, emergency visits, or other specific techniques or treatments. Although these costs are difficult to quantify for hospital pharmacies, they are one of the main problems in chronic diseases." 
Table 2 Mean scores, standard deviations and main comments from study participants for each criteria of the MCDA framework (Continued)

\begin{tabular}{|c|c|c|}
\hline MCDA framework criteria & $\begin{array}{l}\text { Mean score } \pm \text { Standard } \\
\text { Deviation }\end{array}$ & Main comments from participants \\
\hline & & $\begin{array}{l}\text { - "The reason for the assigned score is purely estimative, since there are no cost- } \\
\text { efficiency studies, neither with selexipag nor with any other therapeutic } \\
\text { alternative." } \\
\text { "The economic impact of a drug is measured not only by its initial cost or } \\
\text { investment, but by its ability to save in other aspects, so, a priori, selexipag seems } \\
\text { to have a better impact on costs." }\end{array}$ \\
\hline $\begin{array}{l}\text { Comparative other non- } \\
\text { medical costs }\end{array}$ & $2.1 \pm 1.9$ on a scale of -5 to 5 & $\begin{array}{l}\text { - "The ease of administration / therapeutic compliance with selexipag could } \\
\text { represent significant economic savings in the occupational and social sphere of } \\
\text { patients." } \\
\text { "Difficult to estimate the impact on productivity, since the majority of patient } \\
\text { candidates for selexipag or iloprost have a recognized legal incapacity status." }\end{array}$ \\
\hline Quality of evidence & $4.0 \pm 1.2 ;$ on a scale of 0 to 5 & $\begin{array}{l}\text { "I believe that it strictly meets the quality criteria required for a clinical trial, } \\
\text { especially given the difficulties of including patients as it is a low prevalence } \\
\text { disease." } \\
\text { "I believe that the Griphon study is one of the best designed, with the largest } \\
\text { number of patients included, with a broad spectrum of basic treatments (similar } \\
\text { to the usual practice) and with one of the longest follow-up periods to date" } \\
\text { "The scientific evidence provided by the Griphon study is now unquestionable, } \\
\text { well above the existing data for many other medications and marks a new } \\
\text { paradigm within clinical trials in pulmonary hypertension." }\end{array}$ \\
\hline $\begin{array}{l}\text { Expert consensus/clinical } \\
\text { practice guidelines (CPG) }\end{array}$ & $3.4 \pm 1.1$, on a scale of 0 to 5 & $\begin{array}{l}\text { "The current guideline recommendations place selexipag in both functional class } \\
\text { II and III of the WHO, with a high level of evidence (IA). However, no distinction is } \\
\text { made with respect to other oral drugs (endothelin antagonists or } \\
\text { phosphodiesterase inhibitors)." } \\
\text { "The real distinction is made with respect to analogous drugs (prostacyclines), } \\
\text { with an introduction in earlier stages (functional class II), as well as a higher level } \\
\text { of evidence." } \\
\text { "In the clinical guidelines of clinical practice, selexipag is recommended with the } \\
\text { same degree of indication (degree I) as the rest of oral treatments with grade B } \\
\text { evidence, similar to riociguat or macitentan." }\end{array}$ \\
\hline
\end{tabular}

We have only identified one study which uses an on-line MCDA platform, conducted by Garau et al. in Italy [29].

The criteria that contributed the most positively to the overall value of selexipag were "disease severity", "unmet needs" and "quality of evidence". The only criteria that contributed negatively to the product's value was the "comparative cost of intervention". This last result was not surprising as selexipag is a more expensive drug than inhaled iloprost, although, according to the experts, may have some potential savings in medical and non-medical costs.

When considering contextual criteria, selexipag was considered a treatment for PAH aligned with the Spanish national healthcare system's priorities. Study participants considered that no major barriers to patient access should be expected, as PAH is considered a very severe disease with high unmet needs in the context specific to prostacyclin pathway treatments. It was also noted that there is a multidisciplinary interest across healthcare professionals for the approval of new effective treatments for PAH. Experts agreed that the Spanish healthcare system would be prepared for the management of selexipag in real practice and it would have a positive impact on patients.
Evaluation of the value innovative products in Spain is carried out sequentially at different levels with specific objectives in each one of them: national level (focused on pricing \& reimbursement decisions and clinical positioning of the drug), regional level (focused on resources management) and local level (focused on hospital access, prioritisation and utilisation criteria) [30].

In general terms, value assessment of medical treatments in Spain is still based mainly on efficacy, safety and cost criteria. While healthcare evaluation bodies acknowledge the importance of considering additional criteria in their decision-making processes, this is currently neither formally established nor standardised, resulting in the practical application of different approaches at different levels [30].

Official pricing and reimbursement criteria used to include a new drug into the Spanish public reimbursement system, are defined in the article 92.1 of the Royal Decree Law 1/2015 [31]. These criteria can be easily related to those included in MCDA frameworks, showing the importance of a complete value assessment of the product, in order to reduce evaluator and decision makers' uncertainties: severity of the disease (relates to severity of disease criterion), specific needs of certain groups (unmet needs and contextual criteria), therapeutic and 


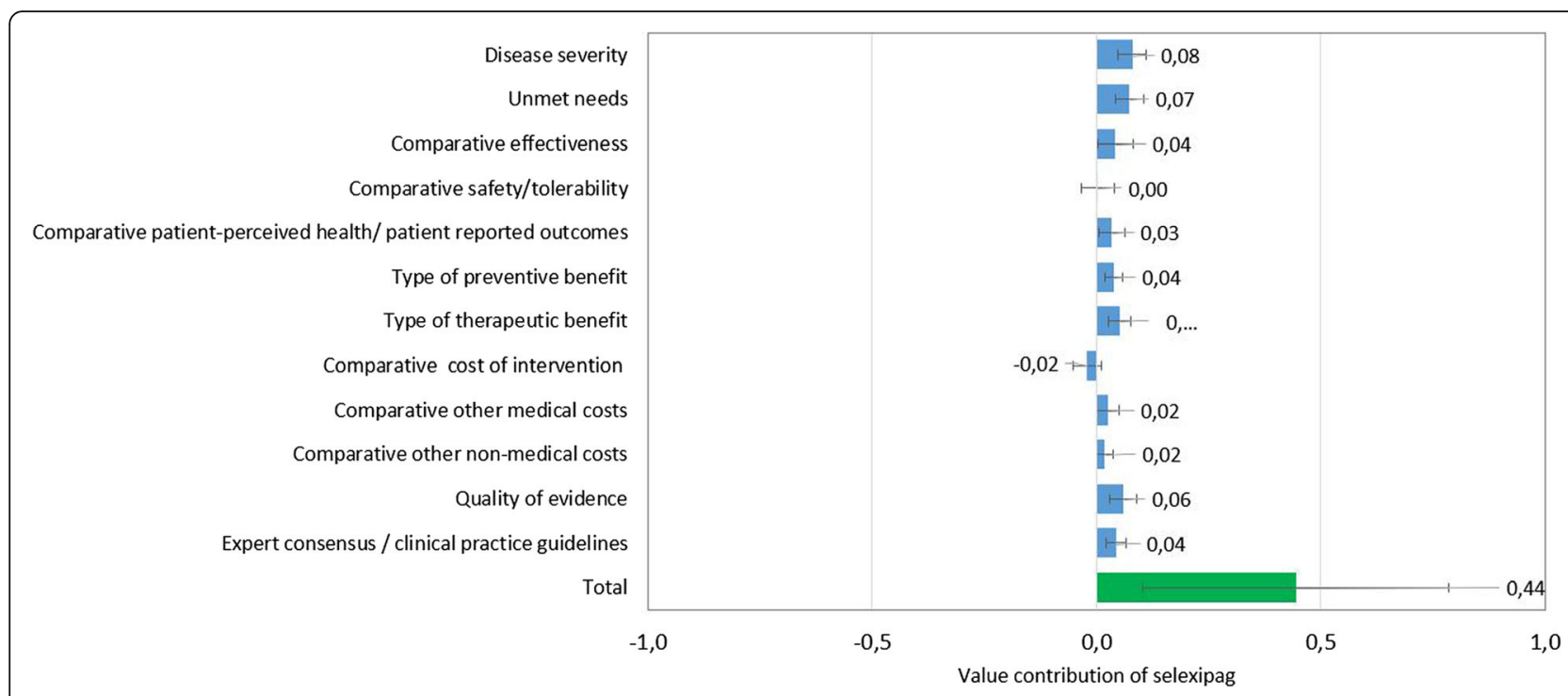

Fig. 3 Weighted value contribution of selexipag for the treatment of PAH compared to iloprost according to quantitative criteria of the adapted MCDA framework. Mean value contributions of each quantitative criterion and overall MCDA value estimates for selexipag in the PAH treatment are shown. Error bars show standard deviations across the 28 study participants

social value and incremental clinical benefit of the medication according to its cost-effectiveness ratio (clinical comparative criteria, therapeutic and preventive benefit, clinical evidence, inclusion in clinical guidelines and contextual criteria), rationalisation of public spending and budgetary impact on the national healthcare system (comparative economic criteria and contextual criteria), existence of alternatives for the same conditions at a lower price or lower treatment cost (unmet needs and comparative cost of intervention criteria) and the drug's degree of innovation (therapeutic benefit criterion). Spanish evaluators and decision makers have already considered the use of MCDA frameworks (and their value criteria) as a complete and useful tool, feasible to be used for drug evaluation and decision-making in Spain [32].
This study provides a multistakeholder value assessment of selexipag, including criteria that can help evaluators and decision makers to assess the overall added value provided by the product in the PAH setting in Spain. MCDA methodology can provide a standardised and holistic value assessment that is valid at all levels, which goes beyond efficacy, safety and cost, especially relevant in complex disease areas (e.g. rare diseases).

This study has some limitations. For the evaluation of some comparative criteria, the available evidence for selexipag and iloprost at the time of the study was limited. Indirect comparisons had to be performed since evidence for both drugs came from studies with very different populations, study design, analytical methodologies and outcome variables. In addition, iloprost has been marketed in Spain since 2004 while selexipag, since

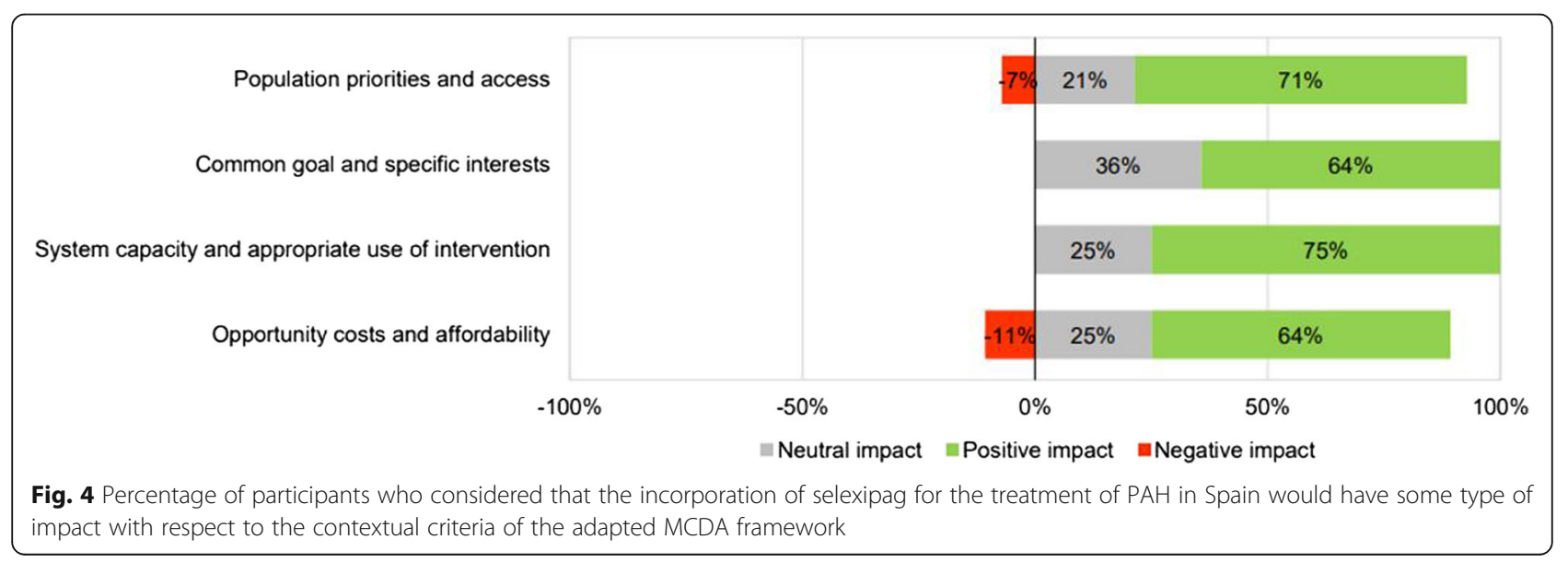


May 2017. Thus, healthcare professionals specialised in $\mathrm{PAH}$ can have a wide practical experience with iloprost and the comparison between the two drugs could be influenced by such previous experience.

The novel design of this study solved one of the major limitations that MCDA value appraisal studies usually present: the small number of experts involved in the study [33]. The sufficiently large number of participants allowed the appraisal to be representative for the whole country and was able to consider a large variety of stakeholder's perspectives and reflections, contributing to study results validity and relevance.

\section{Conclusions}

Selexipag is a selective IP receptor agonist which was the first oral drug approved in Europe for the long-term treatment of PAH in adult patients with WHO functional class (FC) II-III. The participants of the study perceived selexipag as an intervention with a positive value contribution to PAH treatment, that is indicated for a severe rare disease with perceived high unmet needs (mainly with regards to the lack of curative and more effective treatments and a more convenient route of administration and posology), supported by high quality clinical evidence and that has demonstrated improvements in efficacy and patient reported outcomes, with limited additional added value in terms of safety, and some additional costs when compared to inhaled iloprost.

The holistic value contribution of selexipag was successfully assessed by a large multidisciplinary panel of relevant stakeholders for drug evaluation and healthcare decision making in Spain using a web-based extended MCDA form.

To our knowledge, this represents the first example of the use of an on-line platform for a study using reflective MCDA methodology in Spain.

\section{Abbreviations \\ AEMPS: Agencia Española de Medicamentos y Productos Sanitarios; AEs: Adverse effects; Cl: Confidence interval; EMA: European Medicines Agency; EPAR: European Public Assessment Report; EQ-5D: quality of life questionnaire- 5 dimensions; ERA: Endothelin receptor agonist; EVIDEM: Evidence and values impact on decision making; FC: Functional class; IP: Prostacyclin receptor; MCDA: Multi-criteria decision analysis; NO: Nitric oxide; PAH: Pulmonary Arterial Hypertension; PDE: Phosphodiesterase; SD: Standard deviation; VAS: Visual analogic scale; VS: Versus}

\footnotetext{
Acknowledgements

We thank the participation of Pilar Escribano, Antonio Román, María Rodríguez, Alberto Jiménez Morales, Arantxa Ais, Pedro Gómez-Pajuelo, José Luis Trillo, Ignacio Casado Moreno, Enrique de Ramon Garrido, José Luis Velasco Garrido, Francisco José García Hernández, Carmen Pilar Simeón Aznar, Iván Castellví Barranco, María Elvira Barrios Garrido-Lestache, Carlos Andrés Quezada Loaiza, Sergio Alcolea Batres, Pilar Blasco, Miguel Ángel Calleja, Alberto Jiménez Morales, Olga Delgado, María Jesús Lamas, Alicia Herrero, José Luis Poveda, Reyes Abad, Vicente Olmo, José María Recalde and Paloma Acevedo in the present study.

We also thank Evan Davies from Actelion Pharmaceuticals and John

Shepherd from Omakase Consulting for their contribution to the manuscript.
}

We would also like to thank the anonymous referees that helped us with their comments to improve the paper

\section{Funding}

This study was supported by Actelion Pharmaceuticals Ltd., a Janssen Pharmaceutical company of Johnson and Johnson.

\section{Availability of data and materials}

The datasets used and/or analysed during the current study are available from the corresponding author on reasonable request.

\section{Authors' contributions}

AG conceived the idea for the study, designed the MCDA model and carried out the analyses and interpretation of the data in addition to drafting the manuscript. AJ and AA contributed to the development of the manuscript. All authors read and approved the final manuscript.

Ethics approval and consent to participate

Ethics approval was not required as no animals nor humans were involved in this study.

\section{Consent for publication}

All co-authors have consented to publication of this manuscript.

\section{Competing interests}

The authors declare that they have no competing interests.

\section{Publisher's Note}

Springer Nature remains neutral with regard to jurisdictional claims in published maps and institutional affiliations.

\section{Author details}

${ }^{1}$ Hospital Virgen de las Nieves, Granada, Spain. ${ }^{2}$ Hospital Gregorio Marañón, Madrid, Spain. ${ }^{3}$ Actelion Pharmaceuticals Ltd, Allschwil, Switzerland.

${ }^{4}$ Omakase Consulting S.L., Madrid, Spain.

Received: 2 August 2018 Accepted: 28 November 2018

Published online: 10 December 2018

\section{References}

1. Galiè N, Humbert M, Vachiery J-L, Gibbs S, Lang I, Torbicki A, et al. 2015 ESC/ERS guidelines for the diagnosis and treatment of pulmonary hypertension. Eur Heart J. 2016;37(1):67-119.

2. Simonneau G, Galiè N, Rubin LJ, Langleben D, Seeger W, Domenighetti G, et al. Clinical classification of pulmonary hypertension. J Am Coll Cardiol. 2004:43(12 SUPPL): 5S-12S.

3. Peacock AJ, Murphy NF, McMurray JJV, Caballero L, Stewart S. An epidemiological study of pulmonary arterial hypertension. Eur Respir J. 2007;30(1):104-9.

4. Humbert M, Ghofrani H-A. The molecular targets of approved treatments for pulmonary arterial hypertension. [cited 2018 Apr 12]; Available from: http://thorax.bmj.com/content/thoraxjnl/71/1/73.full.pdf

5. Vachiery J-L, Simonneau G. Management of severe pulmonary arterial hypertension. Eur Respir Rev. 2010;19(118):279-87 [cited 2018 May 14] Available from: http://www.ncbi.n/m.nih.gov/pubmed/21119186.

6. Lang IM, Gaine SP. Recent advances in targeting the prostacyclin pathway in pulmonary arterial hypertension. Eur Respir Rev. 2015;24(138):630-41.

7. Safdar Z. Treatment of pulmonary arterial hypertension: The role of prostacyclin and prostaglandin analogs. Respir Med. 2011;105(6):818-27 [cited 2018 May 14] Available from: http://www.ncbi.nlm.nih.gov/ pubmed/21273054.

8. Terap IDEP, Hap L, li-iv CF. Informe de Posicionamiento Terapéutico de selexipag ( Uptravi ${ }^{\circledR}$ ) en hipertensión pulmonar. 2017;1-6.

9. Sitbon $\mathrm{O}$, Channick R, Chin KM, Frey A, Gaine S, Galiè N, et al. Selexipag for the treatment of pulmonary arterial hypertension. N Engl J Med. 2015; 373(26):2522-33.

10. Bayram MM, Walters B. Assessment Report 2008;44(April):1-12.

11. Annemans L, Aymé S, Le Cam Y, Facey K, Gunther P, Nicod E, et al. Recommendations from the European working Group for Value Assessment and Funding Processes in rare diseases (ORPH-VAL). Orphanet J Rare Dis. 2017;12(1):50. 
12. Schlander M, Garattini S, Holm S, Kolominsky-Rabas P, Nord E, Persson U, et al. Incremental cost per quality-adjusted life year gained? The need for alternative methods to evaluate medical interventions for ultra-rare disorders. J Comp Eff Res. 2014;3(4):399-422 [cited 2018 May 4] Available from: http://www.ncbi.n/m.nih.gov/pubmed/25275236.

13. Thokala P, Devlin N, Marsh K, Baltussen R, Boysen M, Kalo Z, et al. Multiple criteria decision analysis for health care decision making - An introduction: Report 1 of the ISPOR MCDA Emerging Good Practices Task Force. Value Heal. 2016;19(1):1-13.

14. Marsh K, IJzerman M, Thokala P, Baltussen R, Boysen M, Kalo Z, et al. Multiple criteria decision analysis for health care decision making--emerging good practices: report 2 of the ISPOR MCDA emerging good practices task force. Value Heal J Int Soc Pharmacoeconomics Outcomes Res. 2016;19(2): 125-37.

15. Gilabert-Perramon A, Torrent-Farnell J, Catalan A, Prat A, Fontanet M, Merino-Montero S, Goetghebeur MMBX. Drug evaluation and decision making in Catalonia: development and validation of a methodological framework based on multi-criteria decision analysis (MCDA) for orphan drugs. ISPOR 20th Annu Eur Congr 4-8 Novemb 2017. Glas Scotl. 2017;1: 111-20.

16. MEDES: el buscador de información médica en español [Internet]. [cited 2017 Jun 5]. Available from: https://www.medes.com/Public/Home.aspx

17. Riva JJ, Malik KM, Burnie SJ, Endicott AR, Busse JW. What is your research question? An introduction to the PICOT format for clinicians. J Chiropratic Assoc. 2012;56(3):167-71.

18. Institute of Medicine (U.S.). Committee on Standards for Systematic Reviews of Comparative Effectiveness Research., Eden J, Levit LA, Berg AO, Morton SC. Finding what works in health care : standards for systematic reviews. [cited 2018 Jun 4]. 317 p. available from: https://books.google.es/books?id= NKcLzMnBOvcC\&pg=PT228\&lpg=PT228\&dq=PICOTS+search+strategy \& source=bl\&ots=jn3PSVCdOh\&sig=awGi-DPe_362P40-Oc2lm_gwFjs\&hl= es\&sa=X\&ved=0ahUKEwjG38Ke07nbAhXD0xQKHVHiDLE4FBDoAQhLMAU\#v= onepage $\& q=P I C O T S$ search strategy $\& f=$ false.

19. EC. EPAR search [Internet]. [cited 2017 Feb 3]. Available from: https://www. ema.europa.eu/en/medicines.

20. AEMPS. TPR search [Internet]. [cited 2017 Feb 3]. Available from: https://www. aemps.gob.es/en/medicamentosUsoHumano/informesPublicos/home.htm.

21. GENESIS-SEFH. Evaluaciones GENESIS [Internet]. 2017 [cited 2017 Jan 1]. Available from: http://gruposdetrabajo.sefh.es/genesis/.

22. CGCOF. Botplus [Internet]. [cited 2017 Feb 3]. Available from: https:// botplusweb.portalfarma.com/.

23. EVIDEM Collaboration. A non profit organisation to promote health through efficient decisionmaking. [Internet]. [cited 2017 Jul 18]. Available from: https://evidem.org.

24. JotForm. JotForm- Template Forms [Internet]. 2017. Available from: https://www.jotform.com/form-templates/.

25. European Medicines Agency. Summary of Product Characteristics. Uptravi (selexipag). 2016;279.

26. European Medicines Agency. Summary of product characteristics. Ventavis (iloprost). 2000;14-6.

27. McKenna SP, Doughty N, Meads DM, Doward LC, Pepke-Zaba J. The Cambridge pulmonary hypertension outcome review (CAMPHOR): a measure of health-related quality of life and quality of life for patients with pulmonary hypertension. Qual Life Res. 2006;15(1):103-15.

28. Rabin R, Oemar M, Oppe M, Janssen B, Herdman M. EQ-5D-5L user guide. Basic Inf how to use EQ-5D-5L Instrum. 2015;(April):28.

29. Garau M, Marsden G, Devlin N, Amedeo N, Profico A. Applying a Multi Criteria Decision Analysis (MCDA) Approach to Elicit Stakeholders Preferences in Italy. The Case of Obinutuzumab for Rituximab Refractory Indolent Non Hodgkin Lymphoma (iNHL). PharmacoEconomics - Open. 2017;11.

30. Badia X, Poveda-Andrés JL, Merino-Montero S. Análisis descriptivo de los criterios usados en los informes de evaluación de fármacos en España. Rev Española Econ la Salud [Internet]. 2017;12(1):180-91 Available from: http://www.economiadelasalud.com/pdf/N12N1/Originales03_ EvaluacionesMCDA.pdf.

31. Ministerio de Sanidad Servicios Sociales e Igualdad. Real Decreto legislativo 1/2015 [Internet]. 2015. Available from: https://www.boe.es/boe/dias/2015/ 07/25/pdfs/BOE-A-2015-8343.pdf.

32. Gilabert-Perramon A, Betolaza J, March J, Espín J, Merino-Montero S, Gil A, et al. Multi-Criteria Decision Analysis (MCDA): common tools for different needs supporting healthcare decision making in Spain. ISPOR 19th Annu Eur Congr 29 October-2 Novemb 2016, Vienna; 2016.

33. Wagner M, Khoury H, Bennetts L, Berto P, Ehreth J, Badia X, et al. Appraising the holistic value of Lenvatinib for radio-iodine refractory differentiated thyroid cancer: A multi-country study applying pragmatic MCDA. BMC Cancer. 2017;17(1):272 [cited 2018 Apr 16] Available from: http://www.ncbi.nlm.nih.gov/pubmed/28412971.

34. PRISMA Flow Diagram. [cited 2017 Aug 4]. Available from: http://prismastatement.org/prismastatement/flowdiagram.aspx.

\section{Ready to submit your research? Choose BMC and benefit from:}

- fast, convenient online submission

- thorough peer review by experienced researchers in your field

- rapid publication on acceptance

- support for research data, including large and complex data types

- gold Open Access which fosters wider collaboration and increased citations

- maximum visibility for your research: over $100 \mathrm{M}$ website views per year

At BMC, research is always in progress.

Learn more biomedcentral.com/submissions 